Article

\title{
Explaining Cooperation in the Council of the EU Before and After the Brexit Referendum
}

\author{
Markus Johansson \\ Department of Political Science, Centre for European Research, University of Gothenburg, 40530 Gothenburg, Sweden; \\ E-Mail: markus.johansson@pol.gu.se
}

Submitted: 30 September 2020 | Accepted: 18 November 2020 | Published: 27 January 2021

\begin{abstract}
This article focuses on the impact of the UK's decision to leave the EU on cooperation within the Council of the EU. It does so by studying how cooperation between member states has changed from the period before the Brexit referendum to the period after. In the emerging literature on Brexit, it has been highlighted that member states that have been close partners to the UK will have to (and have started to) adjust their cooperation behaviour and form new alliances. While the structure of cooperation in the Council is often understood to be stable over time, suggesting that cooperation is mainly driven by structurally determined preferences that don't easily change, a major event such as Brexit may force remaining member states to restructure their cooperation behaviour. Accordingly, it is expected and tested whether less structurally determined preferences have grown in importance for shaping patterns of cooperation in the immediate period following the Brexit referendum. Using survey data based on interviews with member state negotiators to the Council, asking about their network ties, compiled both in the period before and after Brexit referendum of 2016, it is shown that structurally determined preferences are important in both periods and that more volatile ideologically-based preferences on the EU integration dimension and GAL-TAN dimension have become important following the referendum. The article is informative both for those interested in the effects of Brexit on EU institutions, as well as those more generally interested in causes of cooperation patterns in the Council.
\end{abstract}

\section{Keywords}

Brexit; cooperation; Council of the EU; European Union; network analysis

\section{Issue}

This article is part of the issue "What Brexit Means for Europe: EU Institutions and Actors after the British Referendum" edited by Edoardo Bressanelli (Sant'Anna School of Advanced Studies, Italy) and Nicola Chelotti (Loughborough University London, UK).

(C) 2021 by the author; licensee Cogitatio (Lisbon, Portugal). This article is licensed under a Creative Commons Attribution 4.0 International License (CC BY).

\section{Introduction}

The Council of the EU is a core institution and the historical powerhouse of the EU legislature. It is the institution of the EU member state governments, who participate in Council meetings to negotiate joint decisions and legislation. The UK decided through a referendum in 2016 to leave the EU and started the process of secession in 2017. The UK has always been a central player in the EU as one of its three big member states and had a central position also in Council cooperation and negotiation networks (e.g., Johansson, Naurin, \& Lindahl, 2019; Naurin \& Lindahl, 2008). Leaving the EU, and the
Council, is expected to leave remaining member states with a need to adjust to this new cooperative landscape (Huhe, Naurin, \& Thomson, 2020). This is particularly true to those that have traditionally had close relations with the UK, a fact that many of them are also aware of (Johansson et al., 2019). Cooperation and negotiations are dynamic and build on exchange, and if some member states make adjustments by seeking new partners, this is likely to have general effects on the patterns and logic of cooperation in the Council.

The question addressed in this article is: If and how has cooperation in the Council changed from the period before the Brexit referendum to the period after? 
Following this, it seeks to determine whether some explanations have grown or diminished in importance in the period following the Brexit referendum. Cooperation is here understood as relational, and an active and deliberative choice. The article explores this question using survey data whose respondents include representatives of the $28 \mathrm{EU}$ member states to a number of Council preparatory bodies. The survey data hence builds on self-reported cooperation. Two surveys are utilized, one from 2015, i.e., the year before the Brexit referendum, and one from 2018 , i.e., the year after the process of negotiating the withdrawal had begun. To explore if and how cooperation changes, the explanatory power of interest-based factors of both a structural nature and of a more volatile ideological nature are tested. The network analyses performed show that structural preferences are important both before and after the Brexit referendum, but that ideological proximity of governments on the EU integration and GAL-TAN (Green-Alternative-Libertarian and Traditional-Authoritarian-Nationalist) dimensions becomes important only after the Brexit vote. Left-right positioning of governments is not important on any side of the Brexit referendum. These findings are not only of relevance for understanding the impact of Brexit but more generally for understanding cooperation in the Council. It offers a deeper understanding of the structure of cooperation within the Council, and what the commonly found geographical patterns of member state cooperation may be based on.

The article starts with a review of what we already know about the effects of Brexit on the Council, and about cooperation patterns in the Council generally. Following this, expectations are derived about what factors are likely to grow in importance when member states adjust their cooperation behaviour in response to the UK's withdrawal. A presentation of the structure of the data and statistical modelling follows and the empirical results are presented. The article ends with a concluding discussion on the implications of the findings.

\section{Cooperation Behaviour in the Council}

The Brexit referendum and withdrawal negotiations are very recent events, and their effect on cooperation and overall functioning of the EU and its institutions has only been explored to a limited extent. Huhe, Naurin, and Thomson $(2017,2020)$ tested the impact of the UK leaving the EU for both the network relations of remaining member states, but also for the content of policy output. They did so by subtracting the UK from historical data on cooperation and positions taken in legislative negotiations in the Council, showing to what extent policy output would have been different had the UK not taken part in the negotiations, as well as the degree to which the standing of the historically strong allies to the UK are affected when losing this strong partner. Their findings on cooperation patterns corroborate what negotiators themselves report regarding their need to adjust their choices of cooperation partners in the Council, with the close allies of the UK being particularly affected (Johansson et al., 2019).

Following this, the question is how cooperation changes and, in particular, in what direction the member states adjust. That is, are cooperative relations following the same patterns and explanations as before, or do other factors become more prominent in this adjustment process? Also here, Huhe et al. (2020) offer some answers. They show that new ties are formed by those member states who lose standing in the network as a consequence of Brexit, based on the positional proximity to other member states. The positional proximity is determined based on a number of negotiated pieces of legislation in the Council. In short, member states that need to adjust cooperation post-Brexit form new ties with other member states that they have historically held similar policy positions to. Using a similar method, the same authors have, more generally, shown that cooperative ties in the Council network are affected by policy position proximity (Huhe et al., 2018). While informative, these findings beg the more general question of whether there are underlying explanations both for position taking and network formation, and in particular, if and how this has changed after the Brexit referendum. Below, this will be further explored for the network relations of member states.

How cooperation is structured within EU institutions is central to understanding how political decisions are reached. Determining patterns of cooperation among the EU member states within the Council has accordingly been imperative in the study of its operation. There is one major finding that is replicated in most of these studies, regardless of the empirical data used: the importance of member states' geographical proximity. This has historically meant that a north-south pattern was observed (Elgström, Bjurulf, Johansson, \& Sannerstedt, 2001; Kaeding \& Selck, 2005), which was later complemented with an eastern group of member states (Mattila, 2009; Naurin \& Lindahl, 2008; Thomson, 2009). While providing an overall structure to cooperation, geography is less enlightening when searching for causal explanations.

The literature on cooperation in the Council has suggested several explanatory factors for the ties between EU member states of both a culturally-based and interestbased nature (Elgström et al., 2001; Kaeding \& Selck, 2005). Some point to geography as a cultural explanation, but it is here rather believed to mask other variation (cf. Beyers \& Dierickx, 1998). The analysis will therefore be limited to the interest-based explanations for cooperation, which are more clearly defined. Among these are the positional proximity of member states, as discussed above. Such actor alignment has sometimes in itself been used to indicate cooperation (Kaeding \& Selck, 2005; Thomson, 2009), and studies of voting patterns can also be understood as falling in this category with an empirical focus on position taking (e.g., Hagemann, 
2008; Hagemann \& Hoyland, 2008; Hosli, Mattila, \& Uriot, 2011; Mattila, 2008). The results of these studies are diverse. Some suggest that geographical patterns indicate different attitudes to regulation and harmonization on the one hand and financial transfers on the other (Kaeding \& Selck, 2005; Thomson, 2009). Others point to the importance of ideological factors and in particular the left-right dimension (Hagemann, 2008; Hagemann \& Hoyland, 2008). While both are plausible explanations for cooperation, they are only tested on actor alignment, which at best make them indirect indications of more active cooperation.

The literature reviewed has hence shown that cooperation, or actor alignment, is stable over time when it comes to geographical patterns, and has been affected only to a limited extent by enlargement rounds (only adding a geographical cluster). There are indications about the relevance of more deeply rooted structural preferences in member states in studies on actor alignment, which fit well with the findings on historical policy position proximity as an important explanation for cooperative ties. The more volatile political preferences that come from ideological factors, varying with government composition, are critical contenders for explaining cooperation. The empirical evidence for the relevance of ideology that exists to date is inconclusive and has been found only on position taking data based on voting. But if these are crucial factors also when studying data on actual cooperative ties, and whether their importance has changed since the Brexit referendum, will be discussed and analysed below.

\section{Expected Changes in Cooperation Behavior after the Brexit Referendum}

It is well-established that cooperation in the Council is stable over time and largely follows geographical patterns. This geographical structure has persisted even when membership has significantly changed, such as after the eastern enlargement. A null hypothesis founded on this observation should hence be that the same explanations for cooperation will be valid both before and after the Brexit vote, and would also give prominence for structurally determined preferences that are resistant to change in both periods:

HO: The UK's decision to leave the EU will not change cooperation in the Council, and the effects of explanatory variables will be stable across the periods before and after the referendum.

The main hypothesis to be tested against the nullhypothesis is consequently that patterns of cooperation between member states in the Council change after the Brexit referendum. In order to test this, it is necessary to establish what factors that structure and explain the cooperative relations between member states both before and after the Brexit vote. In gen- eral, when searching for explanations for the strength of relational ties-which cooperation is an example ofit is natural to look for ways of measuring similarities and differences between included actors. In theories of social networks among individuals, explanations based on such homophily mechanisms are regularly reported to be strong predictors of network relations (e.g., Grund \& Densley, 2012). There are strong preference-based motifs for choosing relations based on similarity, not least in a decision-making setting such as the Council. This characteristic of network relations hence also serves as a baseline assumption here.

Knowing that cooperation patterns in the Council have historically been stable, it is expected that similarities between member states that are more structurally determined should be important. Thomson (2009), as well as Kaeding and Selck (2005), has shown that member states that take similar positions in the EU Council belong to different geographical clusters, and based on this observation inferred that this might be caused by shared attitudes to regulation and financial transfers. They base this on a general understanding of the member states belonging to the different geographical clusters. I attempt here to take this suggestion one step further, by arguing that member states have different, historically rooted, preferences on the degree of state intervention in the economy that are not rapidly changing. These preferences are here also believed to be crucial determinants for the type of regulatory systems that member states want in the EU, and should therefore also be important for their cooperative ties in the EU, and the Council specifically. The argument is based on an understanding of policy conflict that emanates from the literature on Varieties of Capitalism (VoC; e.g., Hall \& Soskice, 2001). In short, this literature separates state systems on a spectrum from Coordinated or Social Market Economies to Liberal Market Economies, capturing different degrees of state intervention in the economy through indications such as taxation, social expenditure, and overall regulation. $\mathrm{VoC}$ has previously been shown to be an important determinant for the structure of member state conflict in the EU, both in treaty amending processes (Fioretos, 2001) and in the EU Court of Justice (Larsson \& Naurin, 2019). Its impact on how the Council operates has not been tested.

It has been argued that the UK's decision to leave the EU forces the remaining member states, particularly those who had previously had strong ties to the UK, to seek new partners in the Council (Huhe et al., 2020; Johansson et al., 2019). As the relevant relations along the $\mathrm{VoC}$ dimension are believed to already have been established before the Brexit vote, any new relations should be expected to be found along other dimensions. That is, instead of moving further away on the VoC dimension when seeking new partners, as these will inevitably be decreasingly similar and previously deemed less relevant, it is expected that the member states will look elsewhere for these new relations. Also here, a 
reasonable expectation is that the member states will follow the homophily logic outlined above and that new cooperative relations will be established between member states that have similar preferences. The main contending preference-based dimension is ideology, which is here expected to become increasingly important when member states adjust to the new cooperative space in the Council after the UK's decision to leave. While previous research has found some, yet limited, evidence of the importance of ideology for position-taking in the Council (Hagemann, 2008; Hagemann \& Hoyland, 2008), it might hence be that the adjustment process triggered by the Brexit vote forces the member states to seek new relations on this dimension, at least in the shortterm. In short, structural preferences-here conceptualized through $\mathrm{VoC}$-are expected to be important in the period both before and after the Brexit referendum, but ideologically-based explanations will grow in importance in the period after the referendum:

$\mathrm{H1}$ : The UK's decision to leave the EU will change cooperation in the Council, and in particular the explanatory strength of ideology will grow in the period after the referendum.

Which the relevant ideological dimensions are, and when, for policy positioning in the EU is disputed. The left-right dimension is a baseline dimension for mapping party-political conflict (Hagemann \& Hoyland, 2008), but it has been complemented with an EU integration dimension, also when analysing the Council (Mattila, 2004). In addition, when studying voters and political parties, it is increasingly common to also include some culturally oriented dimension, such as GAL-TAN (Hooghe, Marks, \& Wilson, 2002). The left-right dimension captures political actors' socio-economic attitudes, the EU integration dimension captures political actors' general view on furthering European integration, whereas the GAL-TAN dimension captures political actors' general attitudes on more culturally-oriented issues and values, separated in a divide between libertarianism and traditionalism. The three dimensions are not completely distinct but often shown to be correlated, either in a linear or curve-linear form (e.g., Costello, Thomassen, \& Rosema, 2012; Hooghe et al., 2002). All three dimensions will be included in the empirical analyses below to evaluate $\mathrm{H} 1$.

\section{Data and Statistical Modelling}

The data used to test the hypotheses comes from The Negotiations in the Council of the European Union Dataset (Naurin, Johansson, \& Lindahl, 2020). The dataset builds on an interview survey with member state representatives to a number of Council preparatory bodies, which was conducted triennially from 2003 to 2018. The survey questions posed have varied somewhat in the different rounds, but one central question was posed in all which asked about the respondent's cooperation part- ners in the Council. This question forms the basis for the dependent variable, as discussed below, and straightforwardly asks: Which member states do you most often cooperate with in order to develop a common position?

To explore whether the Brexit referendum has had an impact on cooperation in the Council, the two latest rounds of the survey conducted in 2015 and 2018 were used. This allows comparison of cooperation patterns and associated explanations in the period before the Brexit referendum in 2016 to the period after. The 2015 round was conducted from October to December, so was concluded around six months before the referendum, and the 2018 round was conducted between April and July, when negotiations on the exit terms had been going on for around a year (the actual negotiations started only after the UK's general election in June 2017). When the 2018 round was conducted, the remaining member states can be expected to have started to view Brexit as a reality, and if Brexit changes cooperation in the Council, it should be possible to observe it by this point in time. It is important to note that there is, as yet, no survey conducted after Brexit and that British representatives were included in the 2018 survey round. More long-term effects will therefore need to be the subject of future studies.

It is worth emphasizing that it is not possible to establish any causal effect of the Brexit vote on cooperation using this data, but only to observe if there are any changes in cooperation between the period before the referendum and the period after. But, if any changes in cooperation were observed, it would be natural to attribute these to significant events during the period between the two points of measurement. There are of course other events during the period of study (2015-2018) that might affect cooperation too, for instance, the unfolding of the migration crisis in 2015, which began during the first of the two survey rounds under study. Both the migration crisis, with its political repercussions, and the Brexit vote can, in turn, be seen as part of the growing politicization of the EU. Some have argued that this politicization can lead to a democratization of the EU, building up the polity and making political conflict increasingly party-based (cf. de Wilde, 2011; de Wilde \& Lord, 2016; Zürn, 2016). While it is not obvious that this leads to increased ideological conflict in the EU, it is sometimes indicated that it could be a logical consequence (e.g., Börzel \& Risse, 2009; de Wilde, 2011; Hooghe \& Marks, 2009). Any shift towards more ideologically-driven cooperation in the Council might hence have been already underway in 2015. However, even if the migration crisis and general politicization trends might be moving the EU member states in a more ideological direction, the subtraction of a member state can be expected to act as a trigger forcing other member states to actually start searching for new cooperation partners. Existing studies on how the Council is affected by the Brexit vote have also shown that remaining member states are adjusting their cooperative relations (Huhe et al., 2020; Johansson et al., 2019). 
In each survey round, all member state representatives to eleven selected preparatory bodies were asked to participate. The targeted preparatory bodies were selected to give a broad coverage of policy areas and levels of seniority in the Council. The preparatory bodies covered in 2015 were: Coreper I, Coreper II, Political and Security Committee, Special Committee of Agriculture, Economic Policy Committee, Politico-Military Group, Working Party on Tax Questions, and Coordinating Committee in the area of policy and judicial cooperation in criminal matters, Working Party on Agricultural Questions, Working Party on Competitiveness and Growth, and the Working Party on the Environment. The same bodies were covered in 2018, with the exception of the Working party on Agricultural Questions, which was replaced with the Working Party on Horizontal Agricultural Questions. The sample hence covers both senior groups of general scope such as Coreper I and II, and more technical working parties in areas such as environment and taxes. Both the 2015 and 2018 survey round targeted 308 member state representatives (28 member states $\times 11$ preparatory bodies), of which 225 and 251 respondents participated in an interview with response rates of $73 \%$ and $81 \%$, respectively (although they varied somewhat between preparatory bodies and member states).

The dependent variable for the analyses is based on the question of cooperation partners. The respondents were asked to mention at least three member states, but there is variation in how many they did, in fact, mention. Based on the order that other member states were mentioned, scores are assigned to the receiving member state, starting with 10 points for a first mention, 9 points for a second mention, and so forth. To give each respondent the same weight in the data, their scores were then standardized to a share of scores, ranging from 0 to 1 , meaning that if one respondent only mentions one other member state and hence gives it 10 points, that member state will receive a score of one, whereas a 10 point score from a respondent that mentioned two member states will only be worth 0.53 (and the 9 will be worth 0.47). These scores were then aggregated for each member state so that the value of each outgoing tie in the resulting member state network is the share of scores that respondents from that sending member state gave to each of the receiving member states. Based on these data on the strength of ties in each dyadic relation, a network of the member states can be mapped and analysed. The analyses of the networks in this article are done using the nwcommands package in Stata (Grund, 2015). The networks from 2015 and 2018 are mapped in Figure 1, where the size of the nodes is based on the sum of aggregated cooperation scores received, which hence indicates the member states' strength in the network. The aggregated cooperation scores (the sum of incoming scores from other member states) are also displayed in Table 1, ranked by the 2018 values. It should be noted that not all member states have ties to each other, and that some ties are not reciprocal but unidirectional. In the 2015 network, there are 87 reciprocated ties and 141 unidirectional ties, and in 2018 there are 123 reciprocated ties and 140 unidirectional ties. However, even when ties are reciprocated in the network, they can still be unbalanced in value, meaning that the reciprocity here is not based on equality. Given that the respondents often mention only a few cooperation partners, there will inevitably be a bias towards the most important relations, and it is hence worth to note that it is the strength of the network ties that is measured and that less important (yet existing) ties may go undetected with this method.

The independent variables measure, on the one hand, the different types of VoC of member states, and on the other hand, the ideological positions of
2015

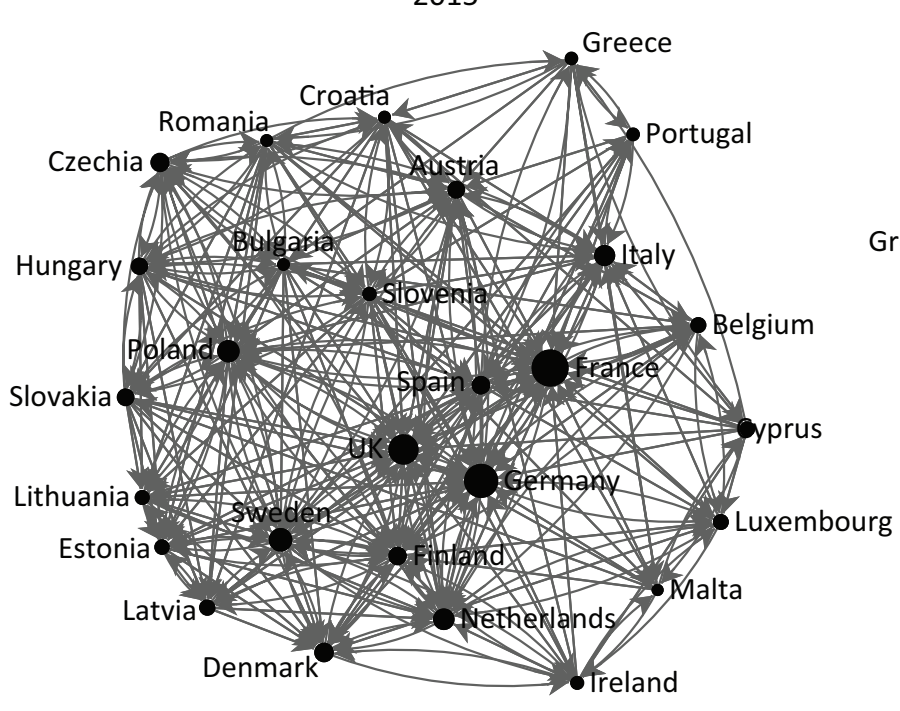

2018

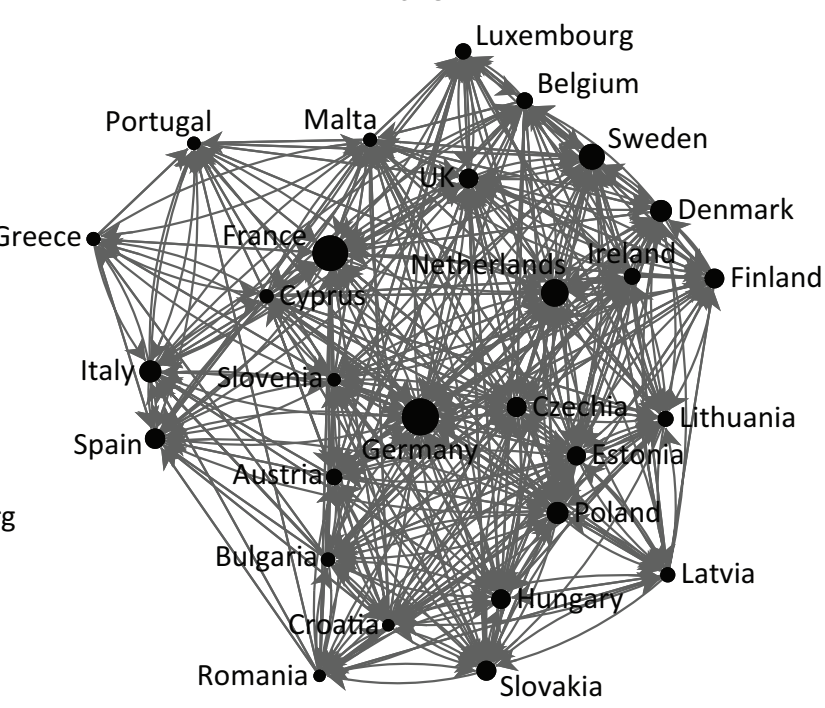

Figure 1. Network of member state relations in the Council 2015 and 2018. 
Table 1. Member states' aggregated cooperation scores in 2015 and 2018.

\begin{tabular}{|c|c|c|}
\hline Member state & Cooperation score 2015 & Cooperation score 2018 \\
\hline Germany & 2.88 & 3.00 \\
\hline France & 3.23 & 2.86 \\
\hline The Netherlands & 1.37 & 1.93 \\
\hline Sweden & 1.61 & 1.76 \\
\hline Italy & 1.32 & 1.33 \\
\hline Poland & 1.48 & 1.32 \\
\hline Denmark & 1.13 & 1.32 \\
\hline Spain & 1.01 & 1.15 \\
\hline Czechia & 1.07 & 1.10 \\
\hline Slovakia & 0.89 & 1.10 \\
\hline Finland & 1.00 & 1.07 \\
\hline UK & 2.40 & 1.07 \\
\hline Hungary & 0.86 & 1.05 \\
\hline Estonia & 0.62 & 0.97 \\
\hline Ireland & 0.45 & 0.73 \\
\hline Belgium & 0.70 & 0.72 \\
\hline Austria & 0.90 & 0.70 \\
\hline Luxembourg & 0.69 & 0.66 \\
\hline Lithuania & 0.58 & 0.65 \\
\hline Latvia & 0.71 & 0.55 \\
\hline Bulgaria & 0.29 & 0.46 \\
\hline Cyprus & 0.65 & 0.45 \\
\hline Greece & 0.39 & 0.44 \\
\hline Malta & 0.23 & 0.42 \\
\hline Portugal & 0.41 & 0.37 \\
\hline Slovenia & 0.49 & 0.35 \\
\hline Croatia & 0.33 & 0.25 \\
\hline Romania & 0.32 & 0.24 \\
\hline
\end{tabular}

the member state governments. Starting with $\mathrm{VoC}$, it is here measured using three components to capture critical variation in how member states have historically chosen to regulate their economies, as highlighted by Höpner and Schäfer (2012). These are: (1) social protection expenditure as a share of GDP, which covers expenditures on disability, sickness/healthcare, old age, survivors, family/children, unemployment, housing and social exclusion not covered elsewhere (Eurostat, 2020a); (2) total taxation as a share of GDP, which covers receipts of taxes and social contributions (Eurostat, 2020b); (3) collective bargaining coverage, which measures employees covered by valid collective (wage) bargaining agreements as a proportion of all wage and salary earners in employment with the right to bargaining, expressed as a percentage, adjusted for the possibility that some sectors or occupations are excluded from the right to bargain (Visser, 2019). For each component, the data was gathered for 2015 and 2018. Data on collective bargaining coverage were however not available for 2018, so have then been imputed from the nearest available year. It is also missing for some member states in 2015 and so was then imputed based on the means of the nearest available year before and after. Based on these data, a principal component analysis of these three variables (eigenvalue 2.67 and 2.63 respectively) was used to obtain a unidimensional VoC-measure using the predicted values of the first component. Member states with low values are identified as Liberal Market Economies whereas member states with high values are identified as Social Market Economies.

To measure the member state governments' positions on the three outlined ideological dimensions, weighted averages of the positions of cabinet parties at the time of the survey were used. The weights of the parties in the cabinet were obtained from their seat share in parliament. Information on cabinet composition and parliamentary seats was gathered from the ParlGov database (Döring \& Manow, 2019). In cases where several governments were in place during the period of the survey, the government with the longest time in office during the survey period was chosen. To measure the ideological positions of the cabinet parties, the datasets from the Chapel Hill Expert Survey of 2014 (Polk et al., 2017) and 2019 (Bakker et al., 2020) were used. The data from 2019 is missing some parties that were in government in 2018. Data for these parties was then obtained from the 2014 round instead. For a couple of parties, there were no available data in any of the Chapel Hill Expert Survey rounds, so they were omitted from the 
analysis. These parties are however small in size, and their omission is therefore not expected to affect the results. As outlined above, three dimensions of ideological positioning are used to test whether ideology affects cooperation in the Council in the periods before and after the Brexit referendum. These are the left-right dimension, the EU integration dimension, and the GAL-TAN dimension. The political parties' positions on the economic left-right are chosen here, as this is more distinct than the general left-right positioning when testing for other ideological indicators as well. The empirical analyses were however run on the general left-right positioning as well, without altering the results. The variable measuring parties' economic left-right position ranges from 0 (extreme left) to 10 (extreme right), the variable measuring parties' EU position ranges from 1 (strongly opposed) to 7 (strongly in favour), and the variable measuring the GAL-TAN position ranges from 0 (libertarian/postmaterialist) to 10 (traditional/authoritarian).

When testing explanatory variables in network analysis, it is the dyadic relation between any two nodes in the network that is analysed. In the networks analysed here, each node represents a member state. In a network with 28 nodes (member states), these dyadic relations amount to 378 , with twice the number of directional ties (756). Since the ties in the network analysed here can be both unidirectional and unbalanced, it is the 756 directional ties that are of interest. For the analysis, this means that the network is transformed to a dependent variable with these 756 directional ties as observations, each measuring the strength of an outgoing tie in the network (e.g., the strength of the tie from Sweden to Denmark). The same logic underlies the construction of the independent variables. When, as in this case, the independent variables do not have a network character, but only hold a value for each member state, the variables are, in a first step, used to create what can be understood as an artificial network based on the absolute distance between any two of the member states' values on the independent variable (e.g., the distance on VoC between Sweden and Denmark). This artificial network contains the same number of directional ties as the cooperation network, but unlike the cooperation network, each relation is completely balanced. Meaning that while the value of the outgoing cooperation tie from Sweden to Denmark can differ from the value of the outgoing cooperation tie from Denmark to Sweden (they are unbalanced), the distance between the same two member states on $\mathrm{VoC}$ will be identical and hence balanced. This setup, however, makes it possible to test whether the strength of a cooperation tie from one member state to another is affected by the corresponding difference in value on the independent variable for the two member states. The artificial networks created from the independent variables are hence regressed on the actual cooperation network. To test the significance of the correlation between independent variables and the cooperation network, a $p$-value is given using a Quadratic Assignment Procedure. What this procedure does is that it creates a series of networks that randomly redistribute the nodes of the existing network (permutations) to test whether the observed correlation between the independent variable and the network is significantly different from the correlations generated by the randomized network. These permutations are hence used to test whether a correlation exists by chance or not (cf. Grund \& Densley, 2012).

\section{Results}

Before evaluating which, if any, of the independent variables explain cooperation patterns before and after the Brexit referendum, it is worth noting the similarities and differences of the networks plotted in Figure 1. One directly visible change, also shown in Table 1 , is the (expected) decreasing position of the UK in the network. While still on the upper half of the ranking of member states when it comes to their total network capital, it has a strikingly more limited strength in the network in 2018 compared to 2015 . Also, following the expectation about the stability of cooperation patterns in the Council, there is a strong correlation between the two networks (0.77). Despite there being a large similarity, there is no complete overlap, suggesting that there is important variation between the two survey rounds which is worth exploring. The strength of the correlation between the networks of 2015 and 2018 is in parity with the correlation between the networks in 2012 and 2015. This proves the stability of the networks but is a bit surprising in light of the expectation that Brexit will be a major event affecting cooperation in the Council (Huhe et al., 2020; Johansson et al., 2019), and is an indication that the Brexit vote has not had an exceptionally large effectyet. The point here is, however, not to evaluate changes taking place between 2012 and 2015, and what might explain them, but instead to note that there do seem to have been changes in the network over the studied period. How cooperation changed between the period before the Brexit referendum and after is evaluated here using the outlined independent variables.

The results from the network analyses based on OLS estimation are displayed in Table 2 . What is evaluated in each model is the relation between the strength of a network tie between two member states, and their distance on each of the independent variables. For each of the independent variables, which measure the distance between two member states on that variable, a negative effect is expected on the strength of the network tie. That is, as the distance between two member states increases, the strength of the cooperation tie is expected to decrease, and vice versa. The ideological variables are tested in separate models since they are internally correlated.

The regression results show a significant effect of $\mathrm{VoC}$ that is robust and substantial in all models. Based on the beta coefficients of models 1 and 2 using the 2015 data, 
Table 2. Regression results.

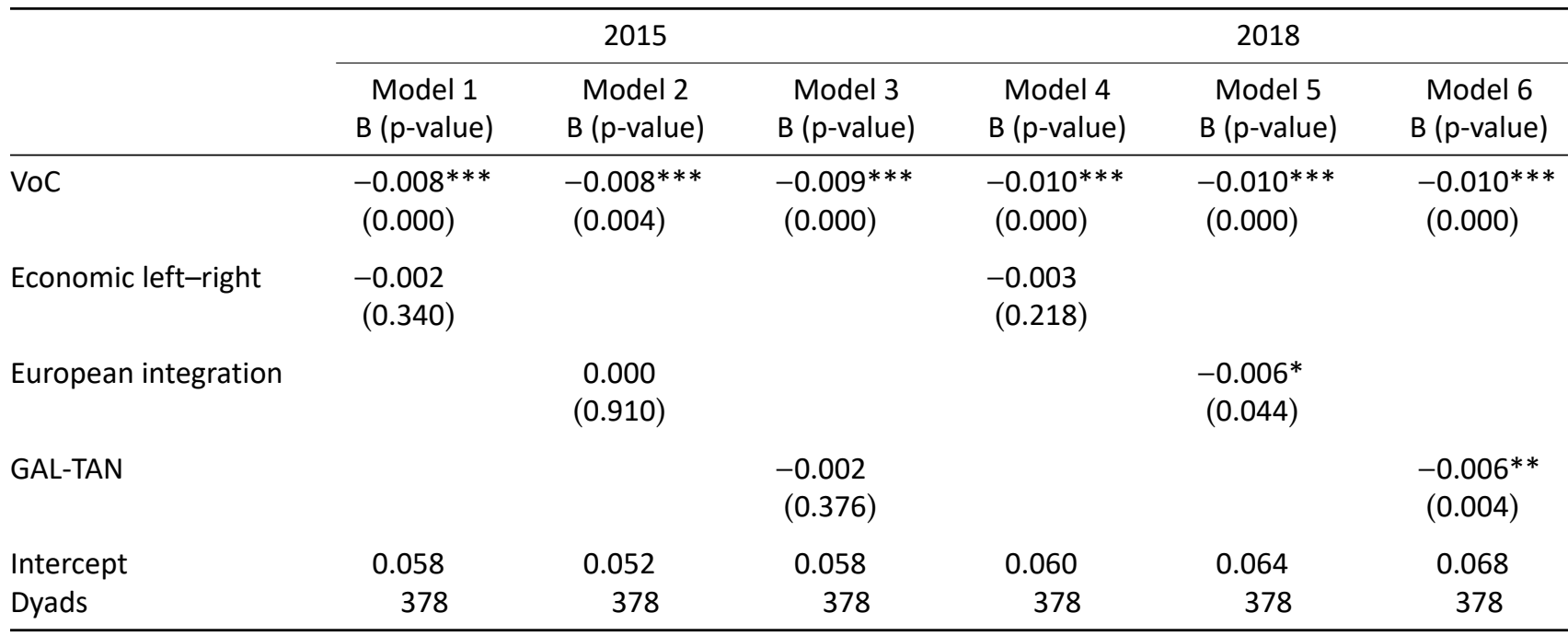

Notes: Dependent variable: strength of cooperation tie. ${ }^{*}=p<0.05,{ }^{* *}=p<0.01,{ }^{* * *}=p<0.001$

the predicted cooperation tie between the most distant member states on VoC in 2015 (Ireland and France) decreases by 0.042 , which corresponds to $8 \%$ of the value of the strongest tie between two member states in the network. The predicted cooperation tie based on the 2018 data decreases by 0.055 , corresponding to $13 \%$ of the value of the strongest tie between two member states in the network. The effect of VoC is hence stable, and if anything, it is becoming more important following the Brexit referendum. The importance of $\mathrm{VoC}$ also explains why there is stability in cooperation patterns in the Council, in line with what previous research has only indirectly suggested (cf. Kaeding \& Selck, 2005; Thomson, 2009). It also offers some clues as to why geography structures cooperation, as $\mathrm{VoC}$ in part follows geographical patterns, with member states on the Liberal Market Economies side of the spectrum being more prevalent in eastern Europe and Social Market Economies in western Europe.

There is no effect of the ideological variables in the 2015 data, but in 2018 a significant effect emerges on both the EU integration dimension and the GAL-TAN dimension. That both these variables become significant simultaneously is not entirely surprising as they too are correlated. Governments that are more closely positioned on the EU integration and GAL-TAN dimension in 2018 hence also have stronger network ties. For the EU integration dimension, UK and Portugal are the most distant member states, and the beta coefficient of model 5 predicts a decrease in the value of their network tie by 0.031 , corresponding to $7 \%$ of the value of the strongest tie between two member states in the network. The equivalent figure on the GAL-TAN dimension (where Malta and Hungary are at the extremes) is 0.043 , which is $10 \%$ of the value of the strongest tie between two member states in the network.

The results offer an indication that cooperation indeed might be changing in the period after the Brexit referendum, and that ideologically driven cooperation becomes more important. The data does not allow any conclusive inferences to be made on whether it is indeed the result of the Brexit referendum or other concurrent events that actually explain the changing dynamic of Council cooperation. But the Brexit referendum is the key event taking place in-between the points of measurement, and we know from previous studies that member states are adjusting cooperation to this new political landscape. In addition, the patterns found follow the logic outlined above, that Brexit forces member states to adjust their cooperation, and in this process they might start to approach member states based on other similarities than the ones that have previously structured cooperation.

It is striking that it is the EU integration and GAL-TAN dimensions that grow in importance in the period after the referendum, and it stands in contrast to the previous findings on ideological cleavages in the Council, which have predominantly pointed to the importance of the left-right dimension (Hagemann, 2008; Hagemann $\&$ Hoyland, 2008). There is a general understanding that European politics have been getting increasingly identitybased over the last decades (e.g., Hooghe \& Marks, 2009, 2018), and it might be that this has now also entered into the traditionally less ideology-infused Council. At the same time, it is worth highlighting that the size of the effect of VoC also increased following the Brexit referendum, indicating that member state representatives are nourishing pre-existing cooperative ties as well.

\section{Conclusion}

This article has explored changes in member states' cooperative relations in the Council of the EU comparing the period before the Brexit referendum in 2016 with the period after. This contributes both to the discussion about the effect of Brexit on the EU and its institutions, 
and more generally to the literature on what shapes cooperative relations between member states in the Council. Cooperative relations in the Council have historically been stable at the aggregate level, and the UK has held a central position in Council networks over time and has ranked high when measuring member states' network capital (Johansson et al., 2019). This position has significantly weakened in the period following the Brexit referendum, indicating not only a decrease in the UK's standing but also that other member states have started to adjust to the post-Brexit cooperative environment in the Council. The question of how the member states have adjusted has been in the focus of this article.

The results clearly show that there is a stable relationship between member states' proximity on the VoC scale and the strength of their cooperative ties. Member states that have historically established similar types of regulatory systems domestically are hence likely to also find common ground in the Council, resulting in a closer cooperative relation. It is plausible that this will continue to be an important determinant for cooperation in the long term, beyond the immediate Brexit years. It hence provides further evidence of the importance of this dimension for member state preferences and policy conflicts in the EU (Fioretos, 2001; Larsson \& Naurin, 2019). In line with the outlined expectation, the Brexit referendum also seems to affect the structure of cooperation, indicated by the emerging importance of the member state governments' ideological proximity in the period after the Brexit referendum. The EU member states have hence realigned on new dimensions after the UK's withdrawal became a reality, as evident by the significant effects of both the EU integration positions and the GAL-TAN positions of governments. Also, in this respect, the findings offer new insight into the structure of cooperation in the Council. While some previous studies have pointed to the importance of left-right divisions for position taking (Hagemann, 2008; Hagemann \& Hoyland, 2008), this research clearly points to the revival of the EU integration dimension (Mattila, 2004) and the introduction of the GAL-TAN dimension in the Council.

The results presented here should not be taken as conclusive evidence that the Brexit referendum is the cause of the growing importance of these ideological dimensions, but it has been demonstrated that these are coincidental trends. The Brexit vote, for instance, happened as the migration crisis and its political consequences unfolded, both of these events can be interpreted as an expression of growing politicization of the EU. The Brexit vote has, however, here been suggested to be a trigger for member states to adjust and seek new cooperative relations in the Council. This is also in line with the findings about the emerging effect of the ideological dimensions. At the same time, the stable, and even growing effect of VoC for cooperation suggests that politicization has not been the only driver of political conflict in this period. Member state relations in the Council remain stable and continue to follow these structural preferences. This is an important complement to the image of an increasingly politicized and changing cooperative space within the EU. Some have suggested that politicization may result in polycleavage, cutting across issues and member states (Zeitlin, Nicoli, \& Laffan, 2019). In light of this, the results shown here might be a sign of an emerging, more complex, conflict space within the EU. Whether it is a persisting trend or only a temporary effect will, however, need to be further explored.

\section{Acknowledgments}

The author would like to express gratitude to Daniel Naurin and Rutger Lindahl for collaboration on gathering the survey data, to Olof Larsson for valuable input to the argument of the article, to the Academic Editors of the thematic issue, as well as to the three anonymous reviewers.

\section{Conflict of Interests}

The author declares no conflict of interests.

\section{References}

Bakker, R., Hooghe, L., Jolly, S., Marks, G., Polk, J., Rovny, J., . . . Vachudova, M. A. (2020). 2019 Chapel Hill expert survey: Version 2019.1 [Data set]. Chapel Hill: University of North Carolina. Retrieved from https:// www.chesdata.eu

Beyers, J., \& Dierickx, G. (1998). The working groups of the Council of the European Union: Supranational or intergovernmental negotiations? Journal of Common Market Studies, 36(3), 289-317.

Börzel, T. A., \& Risse, T. (2009). Revisiting the nature of the beast: Politicization, European identity, and postfunctionalism: A comment on Hooghe and Marks. British Journal of Political Science, 39(1), 217-220.

Costello, R., Thomassen, J., \& Rosema, M. (2012). European Parliament elections and political representation: Policy congruence between voters and parties. West European Politics, 35(6), 1226-1248.

de Wilde, P. (2011). No polity for old politics? A framework for analyzing the politicization of European integration. Journal of European Integration, 33(5), 559-575.

de Wilde, P., \& Lord, C. (2016). Assessing actually-existing trajectories of EU politicisation. West European Politics, 39(1), 145-163.

Döring, H., \& Manow, P. (2019). Parliaments and governments database (ParlGov): Information on parties, elections and cabinets in modern democracies: Development version [Data set]. Retrieved from http:// www.parlgov.org

Elgström, O., Bjurulf, B., Johansson, J., \& Sannerstedt, A. (2001). Coalitions in European Union negotiations. Scandinavian Political Studies, 24(2), 111-128.

Eurostat. (2020a). Total social protection expenditure 
as share of GDP [spr_exp_sum] (indication). Luxembourg: Eurostat.

Eurostat. (2020b). Total taxation as share of GDP [gov_10a_taxag] (indication). Luxembourg: Eurostat.

Fioretos, O. (2001). The domestic sources of multilateral preferences: Varieties of capitalism in the European community. In P. A. Hall \& D. Soskice (Eds.), Varieties of capitalism (pp. 213-244). Oxford: Oxford University Press.

Grund, T. U. (2015). nwcommands: Network Analysis in Stata [Computer software]. Retrieved from http:// nwcommands.org

Grund, T. U., \& Densley, J. A. (2012). Ethnic heterogeneity in the activity and structure of a Black street gang. European Journal of Criminology, 9(4), 388-406.

Hagemann, S. (2008). Voting, statements and coalitionbuilding in the Council from 1999 to 2006. In D. Naurin \& H. Wallace (Eds.), Unveiling the Council of the European Union: Games governments play in Brussels (pp. 36-63). London: Palgrave Macmillan.

Hagemann, S., \& Hoyland, B. (2008). Parties in the Council? Journal of European Public Policy, 15(8), 1205-1221.

Hall, P. A., \& Soskice, D. W. (Eds.). (2001). Varieties of capitalism: The institutional foundations of comparative advantage. Oxford: Oxford University Press.

Hooghe, L., \& Marks, G. (2009). A postfunctionalist theory of European integration: From permissive consensus to constraining dissensus. British Journal of Political Science, 39, 1-23.

Hooghe, L., \& Marks, G. (2018). Cleavage theory meets Europe's crises: Lipset, Rokkan, and the transnational cleavage. Journal of European Public Policy, 25(1), 109-135.

Hooghe, L., Marks, G., \& Wilson, C. J. (2002). Does left/right structure party positions on European integration? Comparative Political Studies, 35(8), 965-989.

Höpner, M., \& Schäfer, A. (2012). Embeddedness and regional integration: Waiting for Polanyi in a Hayekian setting. International Organization, 66(3), 429-455.

Hosli, M. O., Mattila, M., \& Uriot, M. (2011). Voting in the Council of the European Union after the 2004 enlargement: A comparison of old and new member states. JCMS: Journal of Common Market Studies, 49(6), 1249-1270.

Huhe, N., Naurin, D., \& Thomson, R. (2017). With or without you? Policy impact and networks in the Council of the EU after Brexit: Vol. 2017:8epa. Stockholm: SIEPS.

Huhe, N., Naurin, D., \& Thomson, R. (2018). The evolution of political networks: Evidence from the Council of the European Union. European Union Politics, 19(1), 25-51.

Huhe, N., Naurin, D., \& Thomson, R. (2020). Don't cry for me Britannia: The resilience of the European Union to Brexit. European Union Politics, 21(1), 152-172.

Johansson, M., Naurin, D., \& Lindahl, R. (2019). Samarbete och inflytande i EU:s ministerråd [Cooperation and influence in the EU Council of ministers] (Vol 2019:6epa). Stockholm: SIEPS.

Kaeding, M., \& Selck, T. J. (2005). Mapping out political Europe: Coalition patterns in EU decisionmaking. International Political Science Review, 26(3), 271-290.

Larsson, O., \& Naurin, D. (2019). Split vision: Multidimensionality in the European Union's legal policy space. International Studies Quarterly, 63(3), 492-506.

Mattila, M. (2004). Contested decisions: Empirical analysis of voting in the European Union Council of Ministers. European Journal of Political Research, 43(1), 29-50.

Mattila, M. (2008). Voting and coalitions in the Council after enlargement. In D. Naurin \& H. Wallace (Eds.), Unveiling the Council of the European Union: Games governments play in Brussels (pp. 23-35). London: Palgrave Macmillan.

Mattila, M. (2009). Roll call analysis of voting in the European Union Council of Ministers after the 2004 enlargement. European Journal of Political Research, 48(6), 840-857.

Naurin, D., Johansson, M., \& Lindahl, R. (2020). The negotiations in the Council of the European Union dataset [Data set]. https://doi.org/10.5878/cfsv-k581

Naurin, D., \& Lindahl, R. (2008). East-north-south: Coalition-building in the Council before and after enlargement. In D. Naurin \& H. Wallace (Eds.), Unveiling the Council of the European Union: Games governments play in Brussels (pp. 64-78). London: Palgrave Macmillan.

Polk, J., Rovny, J., Bakker, R., Edwards, E., Hooghe, L., Jolly, S., .. . Zilovic, M. (2017). Explaining the salience of anti-elitism and reducing political corruption for political parties in Europe with the 2014 Chapel Hill expert survey data. Research \& Politics, 4(1), 1-9.

Thomson, R. (2009). Actor alignments in the European Union before and after enlargement. European Journal of Political Research, 48(6), 756-781.

Visser, J. (2019). ICTWSS Database: Version 6.0 [Data set]. Amsterdam: Amsterdam Institute for Advanced Labour Studies (AIAS). Retrieved at https://www. ictwss.org/downloads

Zeitlin, J., Nicoli, F., \& Laffan, B. (2019). Introduction: The European Union beyond the polycrisis? Integration and politicization in an age of shifting cleavages. Journal of European Public Policy, 26(7), 963-976.

Zürn, M. (2016). Opening up Europe: Next steps in politicisation research. West European Politics, 39(1), 164-182. 


\section{About the Author}

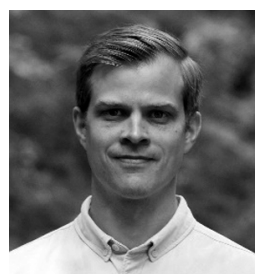

Markus Johansson (PhD) is a Researcher and Lecturer in Political Science at the Centre for European Research (CERGU) and the Department of Political Science at the University of Gothenburg. His research is focused on EU institutions and decision-making, particularly negotiations and cooperation in the Council of the EU, causes and effects of non-compliance in the EU, leadership in the EU, and EU foreign policy. 